\title{
Modeling and Imaging of the Ni-Like Pd X-ray Laser and Other New Schemes
}

\author{
J. Nilsen, J. Dunn, R.F. Smith, T.W. Barbee
}

This article was submitted to

$8^{\text {th }}$ International Conference on X-Ray Lasers, Aspen, CO, May 2731,2002

\section{June 26, 2002}

U.S. Department of Energy

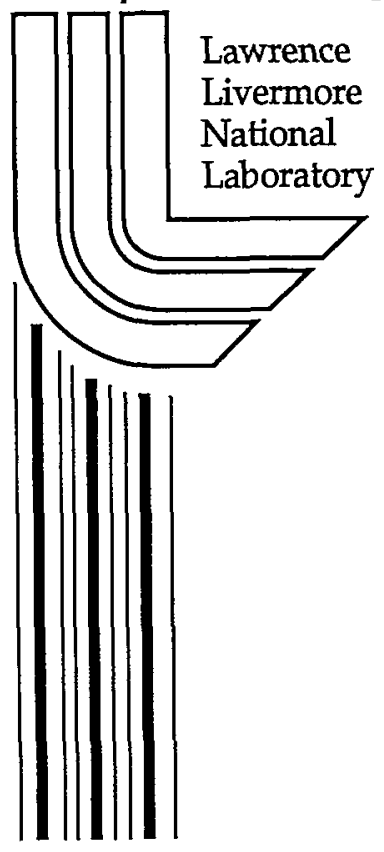




\section{DISCLAIMER}

This document was prepared as an account of work sponsored by an agency of the United States Government. Neither the United States Government nor the University of California nor any of their employees, makes any warranty, express or implied, or assumes any legal liability or responsibility for the accuracy, completeness, or usefulness of any information, apparatus, product, or process disclosed, or represents that its use would not infringe privately owned rights. Reference herein to any specific commercial product, process, or service by trade name, trademark, manufacturer, or otherwise, does not necessarily constitute or imply its endorsement, recommendation, or favoring by the United States Government or the University of California. The views and opinions of authors expressed herein do not necessarily state or reflect those of the United States Government or the University of California, and shall not be used for advertising or product endorsement purposes.

This is a preprint of a paper intended for publication in a journal or proceedings. Since changes may be made before publication, this preprint is made available with the understanding that it will not be cited or reproduced without the permission of the author.

This report has been reproduced directly from the best available copy.

Available electronically at http://www.doc.gov/bridge

Available for a processing fee to U.S. Department of Energy

And its contractors in paper from

U.S. Department of Energy

Office of Scientific and Technical Information

P.O. Box 62

Oak Ridge, TN 37831-0062

Telephone: (865) 576-8401

Facsimile: (865) 576-5728

E-mail: reports@adonis.osti.gov

Available for the sale to the public from

U.S. Department of Commerce

National Technical Information Service

5285 Port Royal Road

Springfield, VA 22161

Telephone: (800) 553-6847

Facsimile: (703) 605-6900

E-mail: orders@ntis.fedworld.gov

Online ordering: http://www.ntis.gov/ordering.htm

OR

Lawrence Livermore National Laboratory

Technical Information Department's Digital Library

http://www.llnl.gov/tid/Library.html 


\title{
Modeling and imaging of the Ni-like Pd X-ray laser and other new schemes
}

\author{
Joseph Nilsen, James Dunn, Raymond F. Smith, and Troy W. Barbee, Jr.
}

\author{
Lawrence Livermore National Laboratory, Livermore, CA $94551-9900$
}

\begin{abstract}
The technique of using a nsec prepulse to create and ionize the plasma followed by a psec pulse to heat the plasma has enabled us to achieve saturated laser output for low- $Z$ neon-like and nickel-like ions driven by small lasers with less than ten joules of energy. In this work we model recent experiments done using the COMET laser at Lawrence Livermore National Laboratory to illuminate slab targets of Pd up to $1.25 \mathrm{~cm}$ long with a 2 joule, 600 ps prepulse followed $700 \mathrm{psec}$ later by a 6 joule, $6 \mathrm{psec}$ drive pulse. The experiments measure the twodimensional near-field and far-field laser patterns for the $14.7 \mathrm{~nm}$ Ni-like $P d x$-ray laser line. This line has already demonstrated saturated output. The experiments are modeled using the LASNEX code to calculate the hydrodynamic evolution of the plasma and provide the temperatures and densities to the CRETIN code, which then does the kinetics calculations to determine the gain. Using a ray tracing code to calculate the near and far-field patterns, the simulations are then compared with experiments.

We also present several new schemes that we are modeling. The first scheme is Pd-like Nd that has a promising $5 d-5 p$ laser line near $24.3 \mathrm{~nm}$ and $5 \mathrm{p}-5 \mathrm{~s}$ lines near $40 \mathrm{~nm}$. Another potential scheme is Pt-like $U$ with $6 \mathrm{~d}-6 \mathrm{p}$ laser lines near 22.5 and $25.8 \mathrm{~nm}$. A Nd-like U laser scheme is also considered.
\end{abstract}

\section{INTRODUCTION}

Most researchers today use some variant of the prepulse technique [1] to achieve lasing in Ne-like or Ni-like ions. As a result the Ne-like $3{ }^{1} \mathrm{~S}_{0} \rightarrow 3 \mathrm{~s}{ }^{1} \mathrm{P}_{1}$ and Ni-like $4 \mathrm{~d}$ ${ }^{1} \mathrm{~S}_{0} \rightarrow 4 \mathrm{p}{ }^{1} \mathrm{P}_{1}$ laser lines now dominate the laser output. This technique illuminates solid targets with several pulses. The prepulse creates a large-scale-length plasma that is in the correct density range for gain and has sufficiently small density gradients for laser propagation. The main pulse then heats the plasma to lasing conditions. In this paper we model the Ni-like Pd experiments performed with the COMET laser at LLNL. The technique at COMET of using a nsec prepulse to create and ionize the plasma followed by a psec pulse to heat the plasma has enabled low- $Z$ nickel-like ions to achieve saturated output when driven by small lasers with less than 10 joules of energy. For the Ni-like Pd experiments we model the $4 \mathrm{~d}^{1} \mathrm{~S}_{0} \rightarrow 4 \mathrm{p}{ }^{1} \mathrm{P}_{1}$ line at $14.7 \mathrm{~nm}$ using the LASNEX [2] and CRETIN [3] codes. These simulations are compared with the experimental measurements of the two-dimensional (2-D) near-field and far-field patterns. 
In the second part of this paper we consider new schemes that may be possible using collisional excitation in isoelectronic sequences other than $\mathrm{Ne}$-like and $\mathrm{Ni}$-like.

\section{PLASMA MODELING OF NI-LIKE PD}

LASNEX one dimensional (1D) computer simulations of a Pd slab illuminated by a $2 \mathrm{~J}, 600$ psec gaussian pulse followed 700 psec later by a $6 \mathrm{~J}, 6$ psec gaussian pulse from a $1.05 \mu \mathrm{m}$ Nd laser is used to model the Pd experiments done at COMET. The calculations assume a $120 \mu \mathrm{m}$ wide by $1.6 \mathrm{~cm}$ long line focus with a 700 psec delay between the long and short pulse. The LASNEX calculations include an expansion angle of 15 degrees in the dimension perpendicular to the primary expansion so as to simulate 2D effects. Since the long pulse is defocused by a factor of 2 in the experiments the long pulse energy in the calculation is reduced to $1 \mathrm{~J}$.

CRETIN calculates the gains of the laser lines including radiation trapping effects for the six $4 \mathrm{f}$ and $4 \mathrm{p} \rightarrow 3 \mathrm{~d}$ resonance lines in Ni-like Pd using the LASNEX calculated densities and temperatures as input. The atomic model of Pd used by the CRETIN code includes all 107 detailed levels for levels up to $n=4$ in Ni-like Pd.

Two dominant laser lines are predicted; the $4{ }^{1} \mathrm{~S}_{0} \rightarrow 4{ }^{1} \mathrm{P}_{1}$ line at $14.7 \mathrm{~nm}$ and the $4 \mathrm{f}{ }^{1} \mathrm{P}_{1} \rightarrow 4 \mathrm{~d}{ }^{1} \mathrm{P}_{1}$ line at $17.0 \mathrm{~nm}$. The Ni-like $4 \mathrm{~d}{ }^{1} \mathrm{~S}_{0} \rightarrow 4 \mathrm{p}{ }^{1} \mathrm{P}_{1}$ line lases by monopole collisional excitation from the ground state populating the upper laser level. The $4 \mathrm{f}^{1} \mathrm{P}_{1} \rightarrow 4 \mathrm{~d}{ }^{1} \mathrm{P}_{1}$ line lases because radiation trapping allows a large radiation field to build up on the $3 \mathrm{~d}^{1} \mathrm{~S}_{0} \rightarrow 4 \mathrm{f}^{1} \mathrm{P}_{1}$ resonance line and populate the $4 \mathrm{f}$ upper laser state by the self-photopumping process [4]. The $17 \mathrm{~nm}$ line is less intense and is observed only weakly in the COMET experiments for Pd but it has been observed more strongly for lower $\mathrm{Z}$ materials such as Mo [4] under the COMET conditions and in $\mathrm{Ag}$ [5] using the P102 laser facility at Limeil. Only the $14.7 \mathrm{~nm}$ line is discussed in this

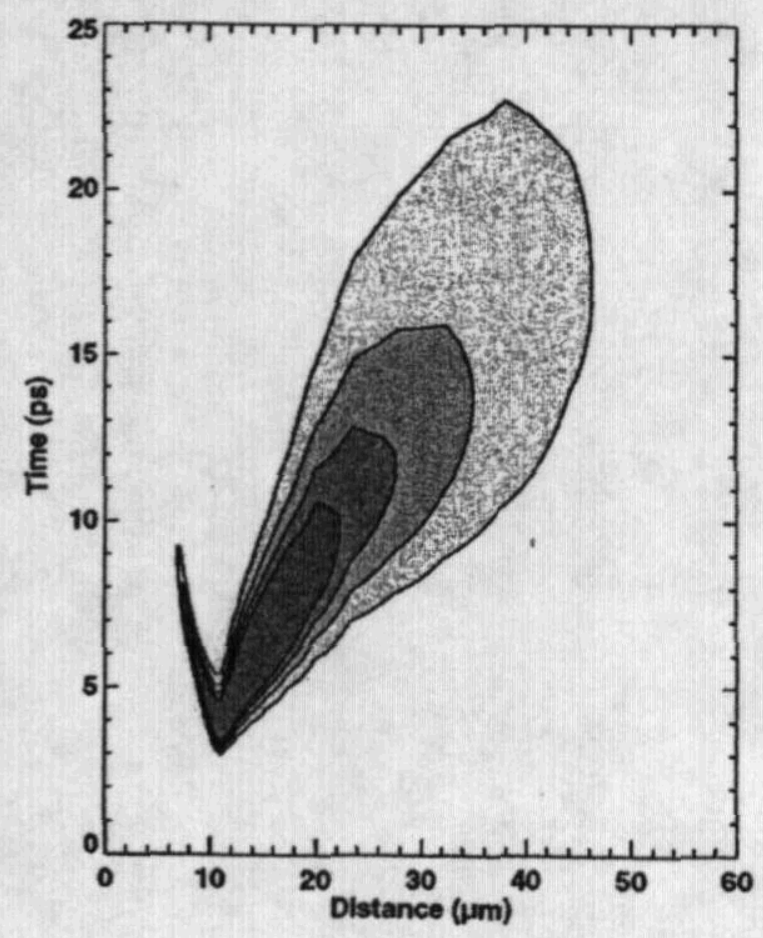

FIGURE 1. Gain contours versus space and time for the Ni-like Pd $14.7 \mathrm{~nm}$ line. 
paper.

Figure 1 shows the calculated contours of the gain versus space and time for the $14.7 \mathrm{~nm}$ line under the nominal drive conditions described above. The short pulse laser peaks at 6 psec on this time scale so the evolution during the long pulse is not shown. The horizontal axis gives the distance from the target surface in the direction of the plasma expansion. The gray scale varies from 0 to $200 \mathrm{~cm}^{-1}$ with the gain contours representing gains greater than $200,150,100$, and $50 \mathrm{~cm}^{-1}$. The darkest contour represents gains greater than $200 \mathrm{~cm}^{-1}$. The calculations predict a very strong gain region 10 to $30 \mu \mathrm{m}$ from the target surface that is similar to what is observed in the experiments.

Given the importance of refraction a ray tracing code was used together with the time and space resolved gain data for the $14.7 \mathrm{~nm}$ line to predict the $1-\mathrm{D}$ near-field and far-field spatial distribution for the $1.25 \mathrm{~cm}$ long Pd laser in the plasma expansion direction. To better match the observed gain we multiplied the gain by 0.25 . The gain multiplier does not affect where the near-field pattern peaks spatially.

Doing a series of ray tracing calculations the simulations predict the peak of the near-field pattern moving from $18 \mu \mathrm{m}$ from the surface for the $0.25 \mathrm{~cm}$ length to $36 \mu \mathrm{m}$ for the $1.25 \mathrm{~cm}$ length. The time and space integrated small signal gain is $33 \mathrm{~cm}^{-1}$ for the short lengths and drops to $19 \mathrm{~cm}^{-1}$ for the longest length due to the refraction effect. Saturation is not included in our calculations. Figure 2(b) shows the normalized near-field pattern that is predicted for the $1.25 \mathrm{~cm}$ long Pd target. The pattern peaks 36 $\mu \mathrm{m}$ from the target surface with a full-width half-maximum width (FWHM) of $8.5 \mu \mathrm{m}$. Note the target surface is at $1 \mu \mathrm{m}$.

Figure 2(a) shows the predicted 1-D far-field pattern. The peak deflection is only $3.5 \mathrm{mrad}$ with a FWHM width of $1.5 \mathrm{mrad}$ in the plasma expansion direction. The beam deflection is very similar to the $3 \mathrm{mrad}$ measured in previous experiments [6]. The divergence is about half the $3 \mathrm{mrad}$ measured in the 2-D far-field images shown in Fig. 3(a).
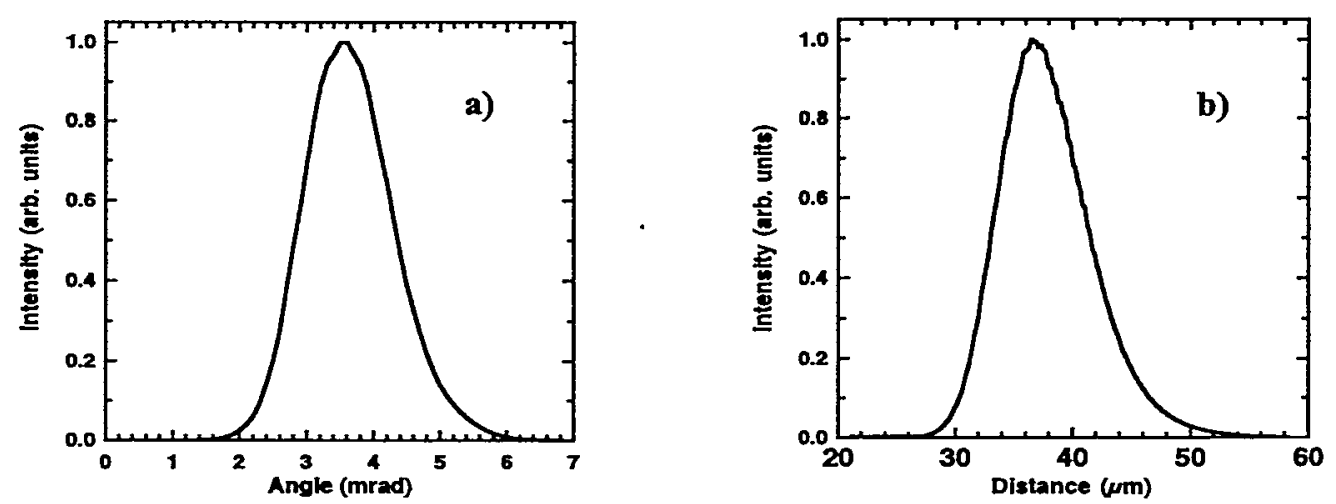

FIGURE 2. Calculated ID far-field (a) and near-field (b) patterns for theit-like Pd $14.7 \mathrm{~nm}$ laser. 


\section{IMAGING EXPERIMENTS IN NI-LIKE PD}

The experiments were performed on the COMET laser system at LLNL. The laser operates at a wavelength of $1054 \mathrm{~nm}$ and utilizes the CPA technique to produce two beams of $500 \mathrm{fs}$ and $600 \mathrm{ps}$ (FWHM) pulse duration. For these experiments the short pulse was lengthened to $6 \mathrm{ps}$ with an energy of 6 to $7 \mathrm{~J}$ while the long pulse energy was typically 1 to $2 \mathrm{~J}$ delivered in the line focus at the target chamber. The laser operates with a repetition rate of 1 shot every 4 minutes. The experiments had the short pulse arrive $700 \mathrm{ps}$ after the peak of the long pulse. This pulse separation was found to be optimum for these experiments. The short pulse beam was focused to 120 $\mu \mathrm{m}$ by $1.6-\mathrm{cm}$ line while the long pulse was defocused by a factor of two to produce a more uniform plasma. A traveling wave irradiation scheme was implemented using seven-segmented stepped mirror to mitigate against the transit time effects. We used a $1.25-\mathrm{cm}$ long polished slab of Pd so that the line focus would overfill the target while maintaining uniform illumination along the entire length.

Having already demonstrated saturated output on the Ni-like Pd laser line at 14.7 $\mathrm{nm}$ in previous work [6], this paper presents the near-field and far-field images of the Ni-like Pd laser line at $14.7 \mathrm{~nm}$. The far-field measurements used 2 flat Mo:Si multilayer mirrors (a $0^{\circ}$ and a $45^{\circ}$ flat mirror) to direct the X-ray laser into the CCD camera which was $130.4 \mathrm{~cm}$ from the end of the target. The measured reflectivity of these two $\mathrm{Mo} / \mathrm{Si}$ multilayer optics was $62 \%$ for the $0^{\circ}$ mirror and $30 \%$ for the $45^{\circ}$ mirror at the laser wavelength with a bandpass of $0.6 \mathrm{~nm}$ and $1.4 \mathrm{~nm}$, respectively, assuming unpolarized X-rays. Thin $\mathrm{Zr}$ filters of thicknesses $190 \mathrm{~nm}$ and $300 \mathrm{~nm}$ were placed before the first multilayer mirror and the CCD camera to block the optical light and to protect the multi-layer mirror from damage. The X-ray back-thinned CCD camera has

a)

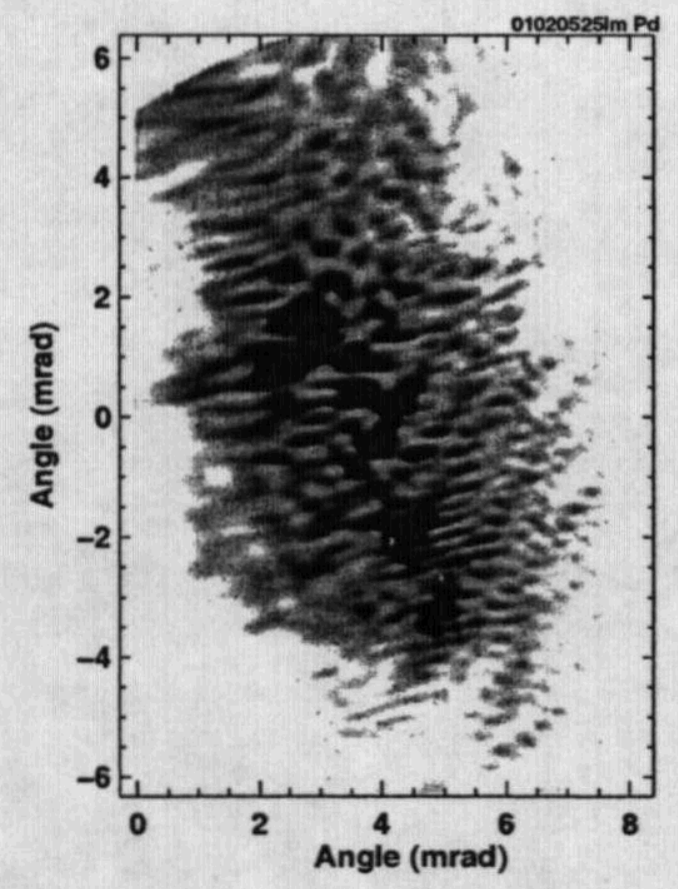

b)

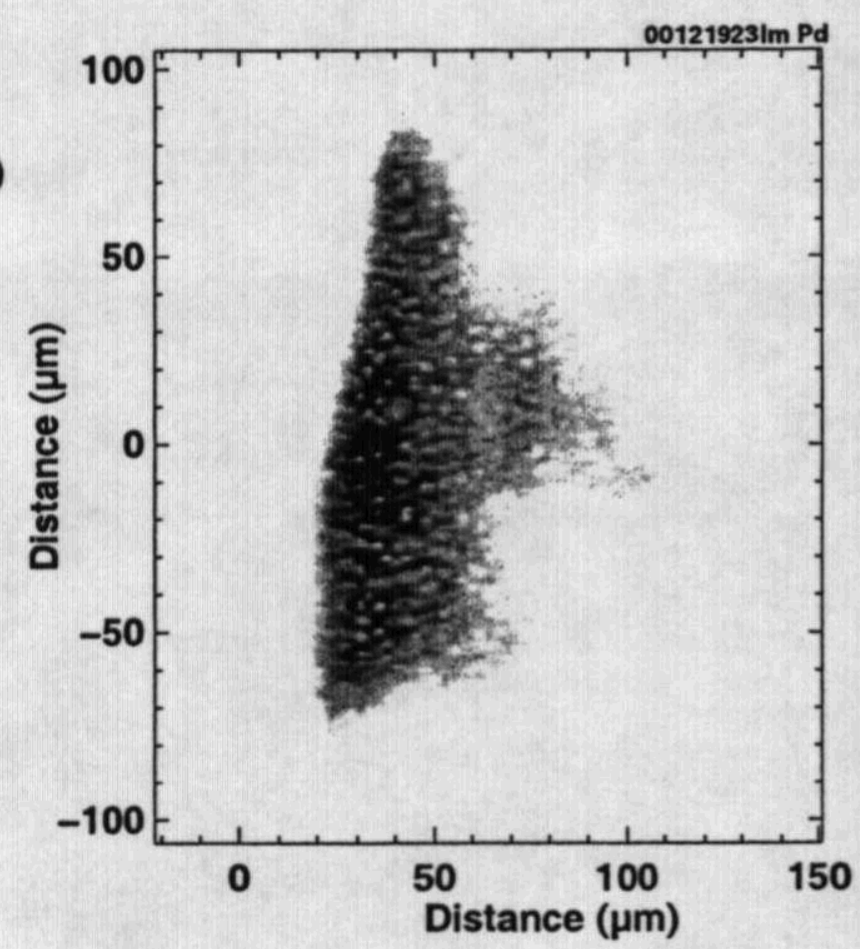

FIGURE 3. Far-field (a) and near-field (b) images of Ni-like Pd $14.7 \mathrm{~nm}$ laser line. 
a 1024 by 1024 pixel array with a $24-\mu \mathrm{m}$ pixel size.

Figure 3(a) shows the far-field pattern for the Ni-like Pd laser using $1.88 \mathrm{~J}$ in the long pulse and $6.67 \mathrm{~J}$ in the short pulse. The horizontal divergence is about $3 \mathrm{mrad}$ in the plasma expansion direction while the vertical divergence is larger, about $6 \mathrm{mrad}$ in the line focus direction. The absolute deflection angle is not measured but previous experiments using a spectrometer measured typical deflection angles of $3 \mathrm{mrad}$ from the target surface [6].

The near-field X-ray laser images used a normal incidence spherical Mo:Si multilayer mirror with a focal length of $11.75 \mathrm{~cm}$ that was placed $12.33 \mathrm{~cm}$ from the end of the Pd X-ray laser target to image the X-ray laser onto the CCD camera with a magnification of 20.1. A filter with $75 \mathrm{~nm}$ thick Al coated on $200 \mathrm{~nm}$ thick Lexan substrate was placed before the imaging mirror while a $295 \mathrm{~nm}$ thick $\mathrm{Zr}$ filter was placed before the CCD camera to block the optical light. The traveling wave mirror was set to $0.67 \mathrm{c}$ for these images which slightly reduces the output of the $\mathrm{X}$-ray laser but the output is still saturated.

Figure 3(b) shows the near-field pattern for the Ni-like Pd laser line at $14.7 \mathrm{~nm}$ using $1.27 \mathrm{~J}$ in the long pulse and $6.58 \mathrm{~J}$ in the short pulse. The horizontal direction is the plasma expansion direction. The laser emission is quite narrow in this direction. The target surface is estimated to be at $0 \mu \mathrm{m}$ on this scale by observing the plasma emission but a better fiducial is needed. The laser emission in the vertical direction is determined by the width of the line focus and is about five times larger than in the expansion direction. Looking at the middle of the line focus the near-field pattern peaks about $35 \mu \mathrm{m}$ from the target surface with a FWHM spatial extent of $24 \mu \mathrm{m}$. This compares very well with the calculated peak $36 \mu \mathrm{m}$ from the target surface. However the calculations have a narrower spatial distribution with a FWHM spatial extent of $8.5 \mu \mathrm{m}$.
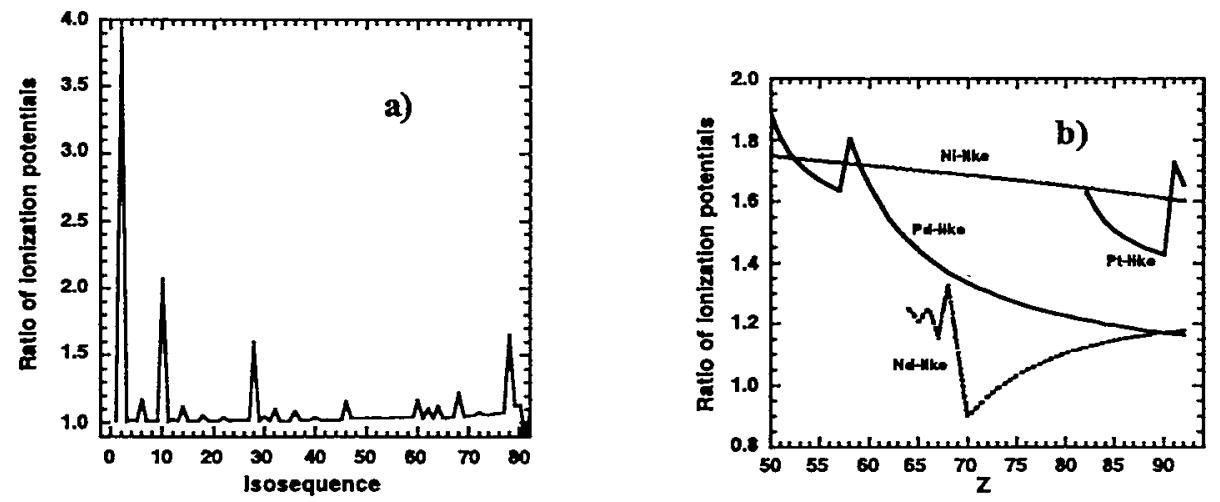

FIGURE 4. Ratio of ionization potentials (a) for adjacent iso-electronic sequences vs uranium isosequences. The ratio of ionization potentials (b) for adjacent iso-electronic sequences vs $Z$ for the Ni-like, Pd-like, Nd-like, and Pt-like sequences. 


\section{NEW SCHEMES}

Given the success of the Ne-like and Ni-like collisional excitation schemes we decided to look at how we could identify other candidate laser schemes. One of the features that make the Ne-like and Ni-like schemes so robust is that there is a large increase in the ionization potential comparing Ne-like to Na-like and Ni-like to $\mathrm{Cu}$-like. This creates the stable ionization balance needed to get population into the ground state of the lasing ion which can then be excited by monopole collisional excitation to the upper laser state. Since Ne and Ni-like have closed $n=2$ and 3 shells the next obvious candidate for a lasing sequence is Nd-like, since that is the fully closed $n=4$ system. However, as Fig. 4(b) will show, there is very little ionization jump with Ndlike because the $5 \mathrm{~s}$ electron is very close to the energy of the $4 \mathrm{f}$ electron. Taking $U$ $(Z=92)$ as an example, Fig. 4(a) shows the ratio of ionization potentials for adjacent sequences vs sequence. For example, for isosequence $=2$ (He-like) Fig. 4(a) plots the value of the ratio for He-like vs Li-like. Looking at this figure one sees the expected peaks at values of 2 (He-like), 10 (Ne-like), and 28 (Ni-like). By looking at this ratio for most sequences and ions we identified 46 (Pd-like) and 78 (Pt-like) as promising new schemes. In fact Pd-like Xe has already been demonstrated as a laser at $41.8 \mathrm{~nm}$ [7]. Fig. 4(b) shows the ratio of ionization potentials for adjacent sequences for $\mathrm{Ni}$ like, Pd-like, Nd-like, and Pt-like versus Z. Keep in mind that the ratio for Ne-like to Na-like is typically 2 to 3 across all ions. Ni-like has a ratio of 1.6 to 1.8 for the ions shown while Nd-like is near 1 , which means no ionization jump. For Pd-like and Ptlike there is a limited range that looks promising. Pd-like has a local maximum near $Z=58$ so we choose to look at Pd-like Nd $(Z=60)$ because of its shorter wavelength. For Pt-like there is a maximum ratio at $Z=91$ but we decided to model Pt-like $U$ $(Z=92)$ because it is useable material and shorter wavelength.

To estimate what lines might lase and at what densities we created atomic models
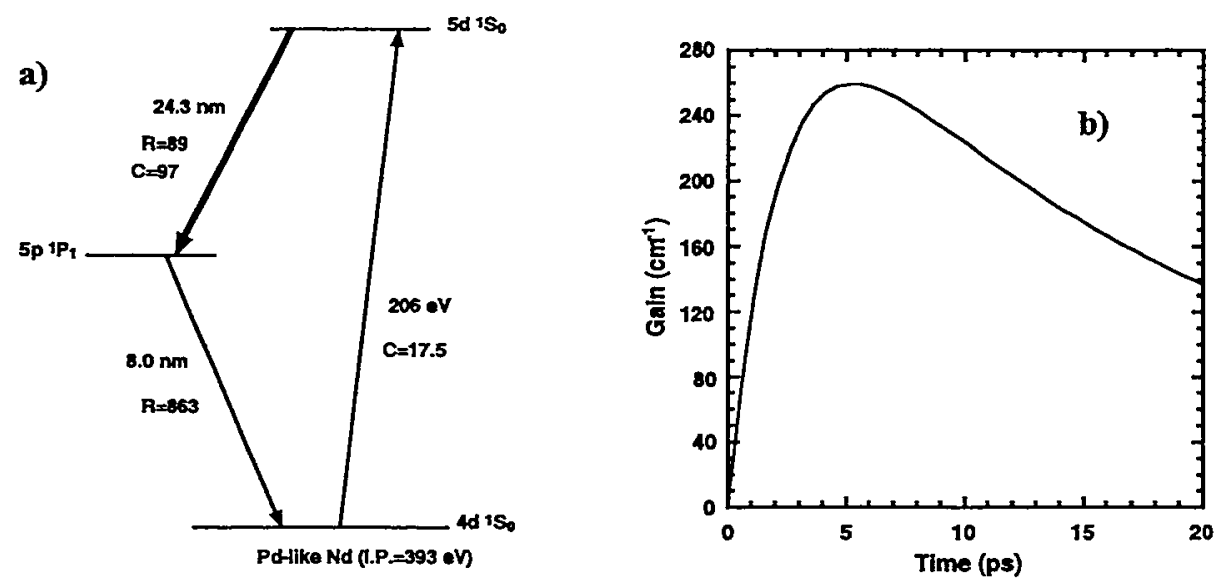

FIGURE 5. Energy level diagram (a) showing the lasing line and kinetic rates for Pd-like Nd laser and the plot (b) of gain vs time for the $24.3 \mathrm{~nm}$ laser line. 
for Pd-like $\mathrm{Nd}$ and $\mathrm{Pt}$-like $\mathrm{U}$ that consisted of only one sequence. An electron temperature near the excitation energy for the monopole excitation was chosen. Putting all the population in the ground state CRETIN was run with different densities to estimate what gain would be present on what lines.

Fig. 5(a) has an energy level diagram for Pd-like $N d$ showing the $5 d^{1} \mathrm{~S}_{0} \rightarrow 5 \mathrm{p}{ }^{1} \mathrm{P}_{1}$ transition that has predicted gain near $24.3 \mathrm{~nm}$. The kinetic rates ( $\mathrm{R}=$ radiative, $\mathrm{C}=$ collisional in $\mathrm{nsec}^{-1}$ ) for an ion density of $10^{18} \mathrm{~cm}^{-3}$, an electron temperature of 250 $\mathrm{eV}$, and an ion temperature of $60 \mathrm{eV}$ are also shown. Since this is the same transition that lases in Pd-like $\mathrm{Xe}$ at $41.8 \mathrm{~nm}$ we did a small correction to the calculated wavelength based on the actual wavelength for Xe. One should note that this transition is analogous to the Ni-like except it is for $n=5$ instead of $n=4$. CRETIN estimates a peak gain of $260 \mathrm{~cm}^{-1}$ that persists for $10 \mathrm{psec}$ as shown in Fig. 5(b). CRETIN also predicts other lasing lines but this is the dominant lasing line in this wavelength range. CRETIN does calculate other strong gain lines but they are near $40 \mathrm{~nm}$.

Creating a similar atomic model for Pt-like U, Fig. 6(a) shows the potential lasing lines and kinetic rates for an ion density of $10^{18} \mathrm{~cm}^{-3}$, an electron temperature of 150 $\mathrm{eV}$, and an ion temperature of $60 \mathrm{eV}$. There are two promising $6 \mathrm{~d}-6 \mathrm{p}$ laser lines at 25.8 and $22.5 \mathrm{~nm}$. The wavelengths are calculated and then an estimated correction has been applied so the actual wavelengths could be off by as much as $1 \mathrm{~nm}$. Using CRETIN to model the kinetics Fig. 6(b) shows plots of the gain for the 2 lines at the above conditions. The gain is largest on the $22.5 \mathrm{~nm}$ line and peaks near $200 \mathrm{~cm}^{-1}$ while the second line has about half the gain. Some preliminary experiments were tried with $U$ on COMET but no sign of lasing was observed yet.

For Nd-like $U$ we also estimated that the $5 f{ }^{1} S_{0} \rightarrow 5 d{ }^{1} P_{1}$ line could have strong gain near $6.7 \mathrm{~nm}$ if one could achieve the correct ionization balance.
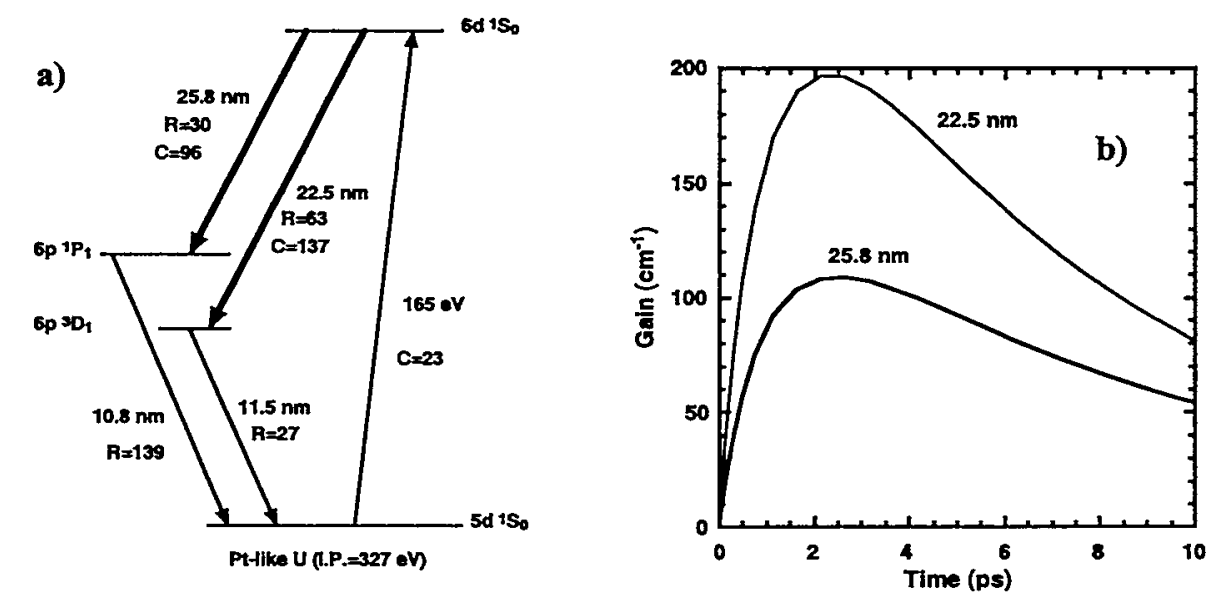

FIGURE 6. Energy level diagram (a) showing the lasing lines and kinetic rates for Pt-like U laser and the plot (b) of gain vs time for the 22.5 and $25.8 \mathrm{~nm}$ laser lines. 


\section{CONCLUSIONS}

This work modeled recent experiments done using the COMET laser at LLNL. We used a $2 \mathrm{~J}, 600$ ps prepulse followed 700 psec later by a $6 \mathrm{~J}, 6 \mathrm{psec}$ drive pulse to illuminate a $1.25 \mathrm{~cm}$ long Pd slab target and produce a saturated $14.7 \mathrm{~nm}$ Ni-like Pd Xray laser. The LASNEX code was used to calculate the hydrodynamic evolution of the plasma and provide the temperatures and densities to the CRETIN code, which then determined the gain from the atomic kinetics calculations including radiation transport effects. Ray-tracing calculations were done to estimate the near-field and far-field images that would be observed in this plasma. The measured two-dimensional nearfield and far-field images were presented for the Ni-like Pd laser and these were compared with the simulations. The $1-\mathrm{D}$ comparison was quite good in the plasma expansion direction.

We also presented modeling of several new laser schemes. The Pd-like Nd scheme has a promising $5 \mathrm{~d}-5 \mathrm{p}$ laser line near $24.3 \mathrm{~nm}$ and $5 \mathrm{p}-5 \mathrm{~s}$ lines near $40 \mathrm{~nm}$. Modeling predicts potential $6 \mathrm{~d}-6 \mathrm{p}$ laser lines near 22.5 and $25.8 \mathrm{~nm}$ for Pt-like U. A Nd-like U laser is also possible near $6.7 \mathrm{~nm}$.

\section{ACKNOWLEDGMENTS}

The authors would like to thank Richard A. Ward, Charles P. Verdon, and Albert L. Osterheld for their support. Work performed under the auspices of the US Department of Energy by the University of California Lawrence Livermore National Laboratory under Contract No. W-7405-Eng-48.

\section{REFERENCES}

1. J. Nilsen, B. J. MacGowan, L. B. Da Silva, and J. C. Moreno, Phys. Rev. A 48, $4682-4685$ (1993).

2. G. B. Zimmerman and W. L. Kruer, Comments Plasma Physics for Controlled Thermonuclear Fusion 2, 51 - 61 (1975).

3. H.A. Scott, JQSRT 71, 689-701 (2001).

4. J. Nilsen, J. Dunn, A. L. Osterheld, and Y. L. Li, Phys. Rev. A 60, R2677 - 2680 (1999).

5. J. Kuba, A. Klisnick, D. Ros, P. Fourcade, G. Jamelot, J. L. Miquel, N. Blanchot, J. F. Wyart, Phys. Rev. A. 62, 043808 (2000)

6. J. Dunn, Y. Li, A. L. Osterheld, J. Nilsen, J. R. Hunter, and V. N. Shlyaptsev, Phys. Rev. Lett. 84, $4834-4837$ (2000).

7. B. E. Lemoff, G. Y. Yin, C. L. Gordon III, C. P. J. Barty, and S. E. Harris, Phys. Rev. Lett. 74, 1574 - 1577 (1995). 